\title{
Pragmatic Difficulties in the Production of the Speech Act of Apology by Iraqi EFL Learners
}

\author{
Mehdi Falih Al-Ghazalli (Corresponding author) \\ Faculty of Arts, al-Mustansiriya University, P.O.Box 46088 \\ Baghdad, Iraq \\ E-mail: mhdiflh2009@hotmail.com \\ Mohanad A. Amert Al-Shammary \\ Faculty of Arts, al-Mustansiriya University, Iraq \\ E-mail: mndhj_87@yahoo.com
}

Doi:10.7575/aiac.alls.v.5n.6p.239

Received: 06/09/2014

URL: http://dx.doi.org/10.7575/aiac.alls.v.5n.6p.239

Accepted: 02/11/2014

\begin{abstract}
The purpose of this paper is to investigate the pragmatic difficulties encountered by Iraqi EFL university students in producing the speech act of apology. Although the act of apology is easy to recognize or use by native speakers of English, non-native speakers generally encounter difficulties in discriminating one speech act from another. The problem can be attributed to two factors: pragma-linguistic and socio-pragmatic knowledge.

The aim of this study is(1)to evaluate the socio-pragmatic level of interpreting apologies as understood and used by Iraqi EFL university learners, (2) find out the level of difficulty they experience in producing apologies and(3) detect the reasons behind such misinterpretations and misuses. It is hypothesized that the socio-pragmatic interpretation of apology tends to play a crucial role in comprehending what is intended by the speaker. However, cultural gaps can be the main reason behind the EFL learners' inaccurate production of the act of apology.

To verify the aforementioned hypotheses, a test has been constructed and administered to a sample of 70 fourth-year Iraqi EFL university learners, morning classes. The subjects' responses have been collected and linguistically analyzed in the light of an eclectic model based on Deutschmann (2003) and Lazare (2004). It has been concluded that the misinterpretation or difficulty Iraqi EFL students have faced is mainly attributed to their lack of socio-pragmatic knowledge. The interference of the learners' first language culture has led to non-native productions of speech act of apology.
\end{abstract}

Keywords: Apology. Difficulty, Production, Recognition, Speech act

\section{Introduction}

It is usually obvious that the reason behind people saying what they say and when they say is to communicate something to their addressees. That is, when speaking, the speaker has a specific intention he/she intends to express to his/her hearer. If this intention is recognized by the hearer, the act of communication can be said to be successful (Bach and Harnish, 1979:3). However, most philosophers of language were, and still are, interested in how language represents the world. Austin's (1962) theory of speech acts, Searle's (1969-1979) revised taxonomy of Austin's categorization system of speech acts, Gricean (1975) pragmatic theory of conversational implicature and Bach and Harnish's (1979) modifications of Austin's and Searle's taxonomies of speech acts constitute the classical contributions to the study of speech acts.

Among many speech acts, the speech act of apology remains of great importance. Norrick (1978: 284) explains the importance of the act of apology in society as it keeps and strengthens relationships between people. Without apology, people would probably be at one another's throats much of the time.

It has been stated that travelling outside one's own speech community involves some experience of miscommunication based on cultural differences. Violating social norms, non-native speakers seem to lack the ability to match a particular form to its equivalent function. Thus, non-native speakers have to take into account the semantic equivalence of these expressions and their communicative functions in both languages.

\section{Definitions}

Goffman (1971: 140) defines remedial apologies as compensatory actions that help restore and maintain social equilibrium and harmony, as he says: "the apology allows the participants to go on their way, if not with satisfaction that matters are closed, then at least with the right to act as if they feel that matters are closed and that ritual equilibrium has been restored". Fraser (1981: 259) believes that remedial apologies are reactions to offences such as violation of social norms or failure to fulfill personal expectations. He (ibid.) proceeds describing the speech act of apology as an 
action held by the apologizer to restore relationship and to change what might be seen as an offensive act into an acceptable one.

However, Leech (1983: 124f) points out that "apologies express regret for some offence committed by S against $\mathrm{H}$... an apology implies a transaction, in that it is a bid to change the balance-sheet of the relation between $\mathrm{S}$ and $\mathrm{H}$ ". That is, as the speaker commits an offence harming the hearer, an imbalance in their relationship is created. Therefore, by apologizing, the speaker tries to restore the balance.

In the same vein, Holmes (1990: 159) presents the following definition of apology:

An apology is a speech act addressed to B's face-needs and intended to remedy an offence for which A takes responsibility, and thus to restore equilibrium between $\mathrm{A}$ and $\mathrm{B}$ (where $\mathrm{A}$ is the apologizer, and $\mathrm{B}$ is the person offended).

However, Gill (2000: 24) maintains that apologies are tools for holding offenders accountable to community, and offenders are assumed to avoid violations in the future which could strengthen the community. Davies, Merrison and Goddard (2007: 41) further elaborate that apologies strengthen the offender's membership of the community and seem to enhance its social standing because apologies mirror the apologizer's understanding and acceptance of the rule violated by the offense and pay face to the addressee, thus paying back the debt of any violation or gaining credit for the future.

Moreover, Lazare (2004: 23) presents a comprehensive definition of the term 'apology'. By this definition, Lazare explains the process in which both the offended and the offender experience the act of apology. He says that:

\footnotetext{
"Apology" refers to an encounter between two parties in which one party, the offender, acknowledges responsibility for an offence or grievance and expresses regret or remorse to a second party, the aggrieved. Each party may be a person or a larger group such as a family, a business, an ethnic group, a race, or a nation. The apology may be private or public, written or verbal, and even, at times, nonverbal.
}

\section{The Components of Apology}

Deutschmann (2003: 44f) claims that most definitions of apology basically contain four components, namely, the offender, the offended, the offence, and the remedy. The offender is the person who commits the act that merits an apology. The offended is the victim of an offense. The offence is the incident which merits the apology. Finally, the remedy, which is the most important component, consists of three sub-components, all of which are essential for carrying out an act of apology. These sub-components are:

1- The offender has to recognize the offence.

2- There has to be some form of acceptance of responsibility on the part of the offender.

3- An apology has to include some form of expression of regret on the part of the offender.

\subsection{Classification of Apologies}

Many classifications of apologies have been proposed by scholars. Each scholar looks at apologies from a different point of view. For example, Deustchmann (ibid, 44ff) distinguishes four types of apologies by which apologizers attempt to remedy different types of offences. These four kinds of apologies are:

1- Real apologies: These are real expressions of regret for non-trivial transgressions.

2- Formulaic apologies: These are uttered where the offence is minimal, i.e. not serious, almost non-existent, and where apologizing is a matter of routine. For example, apologies for social gaffes such as coughing, sneezing, burping, clearing the throat, etc. as well as apologies for slips of the tongue.

3- Formulaic apologies with added functions: These are uttered in situations where the offence is minimal and the apology has other functions in addition to that of repair work. For example, request cues and attention cues.

4- Face attack apologies: These are uttered in situations where the remedial nature of the apology is questionable. For example, sarcastic apologies and apologies that are used for introducing a challenge.

However, Lazare (2004: 38ff) states that apologies can be classified according to the parties involved into two categories: private and public apologies.

1- Private Apologies: These occurred mainly between individuals, i.e. between two persons only without an external audience. Private apologies are characterized by spontaneity, emotionality, flexibility, and responsiveness to reactions 
of the offended person. These apologies can only be effective if the offended person feels that the offender is sincere in his remorse.

2- Public Apologies: These occurred basically between two individuals with extra audience such as apologies between two presidents in the presence of international press, and apologies between two students before the whole class, etc. Public apologies are characterized by being carefully prepared in advance with the help of others. Therefore, public apologies seem to be "less spontaneous, less emotional, and are usually offered in response to public pressure". In order to be effective, public apologies require public declaration of the offence and the restoration for public dignity.

\subsection{Successful Apologies}

To be successful, apologies should be accepted by the offended parties and the damaged relationships should be healed. However, what psychological needs do successful apologies satisfy for the offended parities? Lazare (2004: 44ff) pinpoints that successful apologies heal because they satisfy at least one or more different psychological needs of the offended parties. These psychological needs are:

1- Restoration of self-respect and dignity

2- Assurance that both parties have shared values

3- Assurance that the offences were not their fault

4- Assurance of safety in their relationship

5- Seeing the offender suffer

6- Reparation for the harm caused by the offence

7- Having meaningful dialogues with the offenders

\subsection{Strategies of Apologies}

Many strategies of apologies have been proposed by several scholars. For example, Olshtain and Cohen (1983: 22) claim that there are five strategies for the speech act of apology:

1- An expression of an apology.

I am sorry, forgive me, etc.

2- An Acknowledgement of responsibility.

It's my fault.

3- An explanation.

There was a traffic-jam.

4- An offer of repair.

Let me repair it for you.

5- A promise of forbearance.

I will not do it again.

They (ibid.) further elaborate that any of these strategies can fulfill the function of an apology. Moreover, the first and second strategies can virtually be used in any apology situation and the last three strategies are situation-specific.

However, Lazare (2004: 74ff) introduces a systematic study concerning the strategies used in the process of apologizing. He argues that there are six strategies for apologies. These strategies are:

1- Acknowledging the offence.

2- Communicating certain attitudes and behaviours (remorse, shame, and humility)

3- Offering an explanation

4- Offering reparations

5- Using proper timing

6- Negotiating differences between parties.

\subsection{The Apparent Sincerity Level of Apology}

Bach and Harnish (1979: 51f) hold the view that it is important to make a distinction between serious and casual apologies. However, Deutschmann (2003: 92) claims that the most problematic aspect of apologies is the apparent sincerity level. Deciding the apparent sincerity level of apologies seems to be problematic for various reasons. These reasons are:

1- Expressing his/her own feelings, the speaker is the only one who knows the actual level of sincerity with which an apology is uttered.

2- Important information about the apparent sincerity level of apologies may be conveyed by the tone of the utterance used. 
3- The emotional relationships, which exist between interlocutors, seem to be an important factor by which the sincerity level of apologies could be judged, (Slugowski and Turnbull, 1988: 101f)

Deutschmann (2003: 97) argues that the apparent sincerity level of apologies seems to mirror the function of the apologies. Thus, real apologies remedying serious offences seem to be apparently sincere. Formulaic apologies made for trivial offences appear to be casual. The tone of the face attack apologies caused by 'breach of consensus' seems to be challenging. Finally, sarcastic apologies appear to be made for a variety of offences, such as lack of consideration, breach of expectation, breach of consensus, hearing offences and requests.

However, Lazare (2004: 117f) observes that, to be effective, apologies must be sincere. In private apologies, i.e. in a one-to-one situation, sincerity plays an essential role. However, sincerity plays a less important role in public apologies in which acknowledgments that a social norm was violated has a great social value regardless of sincerity.

\subsection{Failed or Pseudo-Apologies}

Sometimes, the offender party tries to manipulate the acknowledgment stage of an apology so that he/she might reduce or avoid responsibility for the offence. However, this usually results in a failed or pseudo-apology. That is, an apology that, at best, does not heal the damage relationship and, at worst, further offends the aggrieved party. Lazare (2004: $85 \mathrm{ff}$ introduces eight different categories in which statement of the offence may fail. These categories may explain why apologies are, sometimes, disappointing, annoying and insulting. These categories are:

1- Offering a vague and incomplete acknowledgment

2- Using the passive voice

3- Making the offence conditional

4- Questioning whether the victim is damaged

5- Minimizing the offence

6- Using the empathic

7- Apologizing for the wrong party

8- Apologizing for the wrong offence

\section{Description of the Test}

The test of the present study consists of two parts. The first part is the recognition test and the second part is the production test. The test is of two questions. The recognition test consists of two branches (A) and (B). Branch (A) is a multiple choice question and it contains five items. Each item is a situation that calls for an apology and it is accompanied with five answers. Each answer is a statement of apology. The students have to choose the most appropriate answer. Branch (B) is a matching question. It contains two lists: List A consists of Five statements directed from the offended party to the offender party and List (B) consists of Six statements of apology. The students have to match each statement with the appropriate statement of apology. The production part contains ten items. Each item is a situation that calls for an apology. The students have to produce statements of apology to each situation. Table (2) below summarizes the test's items.

\subsection{Population of the Test}

The population of the present study is fourth - year Iraqi EFL university learners, morning classes at the department of English Language and Literature, College of Arts, in two different universities namely: Al-Mustansiriyah University (henceforth Group A) and University of Baghdad (henceforth Group B) during the academic year 2013 - 2014. The total number of the students is 125 in both departments. The randomly chosen sample is 75 students of which 35 students of Group A and 40 students of Group B. Such number constitutes $60 \%$ out of the total number.

\subsection{Administration of the Main Test}

The test was administered to Group A at the Department of English, College of Arts, Al-Mustansiriyah University on May $13^{\text {th }}$ during the academic year $2013-2014$. On the next day, i.e. on May $14^{\text {th }}$, the test was administered to Group B at the department of English, College of Arts, University of Baghdad during the academic year 2013 - 2014.

\subsubsection{Test's Scores}

The tables below present general scores of both group (A) and group (B). These tables explain in detail students' scores in each question aided with rates. Then, a total score for each part of the test, i.e. recognition and production, for both groups is measured.

Table 1. General scores of group A.

\begin{tabular}{cccccc}
\hline Group No. & Type of test & Question No. & $\begin{array}{c}\text { Students' } \\
\text { scores }\end{array}$ & Whole scores & Rate \\
\hline Group A & Recognition & Q1 A & 62 & 150 & $41 \%$ \\
Group A & Recognition & Q1 B & 95 & 150 & $63 \%$ \\
Group A & Production & Q2 & 71 & 300 & $23.6 \%$ \\
& Total & & 228 & 600 & $38 \%$ \\
\hline
\end{tabular}


Table 2. General scores of group B.

\begin{tabular}{cccccc}
\hline Group No. & Type of Test & Question No. & $\begin{array}{c}\text { Students' } \\
\text { scores }\end{array}$ & Whole scores & Rate \\
\hline Group B & Recognition & Q1 A & 86 & 200 & $43 \%$ \\
Group B & Recognition & Q1 B & 133 & 200 & $66 \%$ \\
Group B & Production & Q2 & 89 & 400 & $22.2 \%$ \\
& Total & & 308 & 800 & $38 \%$ \\
\hline
\end{tabular}

Table 3. General scores of group A and B.

\begin{tabular}{cccc}
\hline Type of test & Students' scores & Whole scores & Rate \\
\hline Recognition & 376 & 700 & $53 \%$ \\
Production & 160 & 700 & $22.8 \%$ \\
\hline
\end{tabular}

\subsubsection{Factors of Failure}

While answering the given test, students have faced difficulties in apologizing for the situations that call for apologies. However, many factors lie behind such difficulties. These factors could be syntactic, semantic, pragmatic or sociopragmatic. Therefore, it is important to consider some examples taken from the responses of the production part of the test in order to arrive at a more obvious view concerning these factors of failure of fourth-year students in producing the speech act of apology.

Item 9: You have stepped on someone's toe in the street.

Student (9): It's a horror thing.

Student (16): Sorry for that, you should not put it in the street.

Considering answers for the example above, it seems to be obvious that both student (9) and student (16) lack the meaning of one or two words of the given situation. Clearly, they seem to lack the meaning of the lexical item (toe) that student (9) has used the word "horror" and student (16) has advised "not to put the toe in the street". Consequently, they both have expressed statements which have no relationship with the speech act of apology.

Item 10: You were cut off in the middle of an important phone call to a business colleague. You call him/her back.

Student (33): Sorry, but something urgent happened.

Student (56): Sorry I was busy.

Student (62): Sorry, it was an important thing.

Looking at the answers produced for the given situation above, it is very clear that the students who have given such answers lack some syntactic aspects of English language. Students (33), (56) and (62) have apologized for this situation as if they have already been responsible for the action, which is not the case. They have not recognized that the form "You were cut off" is, in fact, a passive voice form. Instead, they consider this form as an active form. However, this form revealed that the action occurred out of one's hand and there is no need to take responsibility for an action one has not done. Therefore, if they were aware of this syntactic piece of information, they would not fail to answer this item.

Item 4: Your dinner guest reminds you that he is a vegetarian. You have just put a huge steak on his plate.

Student (31): as you like.

Item 8: You have loudly laughed at your classmate's comment in a lecture. You meet him/her later and say:

Student (9): Do you keep a silent in your lecture.

Student (17): Oh, what happen for you in class, you laught loudly in class, be good next time and do not do this again.

Student (23): Try to be careful in another lecture.

Student (31): Oh. It is very nice.

Considering answers given above, it seems clear that those students who have produced these answers have faced difficulties in comprehending the given situation that calls for an apology. However, their answers have revealed that they have misinterpreted the given situation pragmatically. These answers have also revealed that the students' failure is mainly attributed to their lack of semantic and pragmatic knowledge.

Item (2): You are at your friend's house. Accidentally, you break a valuable vase belonging to him/her.

Student (22): Excuse me, but it was an accident by chance.

Student (27): Excuse me, but it was an accident.

Item (3): You have an appointment with your lecturer at his office. You arrived after 40 minutes because there was a traffic-jam.

Student (12): Excuse me for being late. 
The examples above show that those students have mainly been influenced by their first language culture. They have relied totally on their first language in answering these situations that they have used the form "excuse me" instead of " $I$ am sorry".

\subsubsection{Unanswered Items}

Some students not only faced difficulties in producing the speech act of apology required for the given situations that call for apologies but also failed in answering these situations. That is, they left these situations unanswered. This can be attributed to total lack of linguistic knowledge. However, the following tables will explain in detail the number of students who have left some items unanswered. At the same time, they will show the number of students who have answered some items but without presenting any type of apology. That is, they attempt to apologize for the given situations, yet they fail to produce apologetic statements in their answers.

Table 4. Unanswered items and those answered without any apology/ question $1 \mathrm{~B}-$ group A and B.

\begin{tabular}{rcc}
\hline Item number & No response & No apology in the answer \\
\hline 1 & 0 & 0 \\
2 & 0 & 0 \\
3 & 2 & 0 \\
4 & 0 & 0 \\
5 & 2 & 0 \\
\hline
\end{tabular}

Table 5. Unanswered items and those answered without any apology/question 2 - group A and B.

\begin{tabular}{ccc}
\hline Item number & No response & No Apology in the Answer \\
\hline 1 & 0 & 4 \\
2 & 0 & 0 \\
3 & 2 & 1 \\
4 & 10 & 3 \\
5 & 2 & 17 \\
6 & 2 & 2 \\
7 & 3 & 4 \\
8 & 8 & 3 \\
9 & 7 & 2 \\
10 & 6 & 3 \\
\hline
\end{tabular}

\section{Discussion of Results}

In introducing the results, the researchers have followed the procedure of "item-analysis" i.e. each item of the test will be introduced hand in hand with the number of correct and incorrect responses given by the learners. In addition, the possible reasons behind erroneous responses will be highlighted.

1- While answering the test designed for the topic under investigation, Iraqi EFL university students have mostly faced difficulties in both recognition part and production part of the test. Although the percentage of their success in identifying and recognizing speech act of apology scores $53 \%$ as they have scored 376 out of the total score 700 ; their failure in identifying and producing speech act of apology scores $22.8 \%$ as they have scored 170 out of the total score 700 .

2- The students' lack of the social and cultural norms of the target language obliges them to fail in that they try to figure out situations that call for apologies. The lack of such knowledge is seen to be a factor of confusion and then failure.

3- The most difficult item that the students experience in the recognition test seems to be item No. (Q1/B-5), where only ten students out of seventy students have answered it correctly. Yet, the easiest one seems to be item No. (Q1/B-1), where fifty-nine students out of seventy students have given correct answers. Similarly, the most difficult item in the production test seems to be item (Q2/ 6), as only six students out of seventy students have answered this item correctly. However, the easiest item in the production test seems to be item (Q2/ 9), as thirty-seven students out of seventy students have answered this item correctly.

4- As for the total lack of linguistic knowledge, it has been noted that seventeen students have not produced any kind of apology in their answers in item (Q2/ 5). However, eight students have left item (Q2/ 8) unanswered. Yet, they all answer items (Q1/A- 1,2,3,4,5), (Q1/B- 1,2,4) and (Q2/ 2) whether correctly or incorrectly.

5- Some answers seem to be directly controlled by students' first language culture. That is, the students appear to recognize and produce the required illocutionary acts using their culture and not the culture of the target language. However, their illocutionary acts are, in fact, different from those recognized and produced by the native speakers. The result is that they recognize and produce them on the basis of their knowledge of the first language culture.

6- The influence of the first language culture on the recognition and production of the speech act of apology might be seen as negative first language transfer. Negative transfer occurs because the first language forms, norms or principles used in target language production are not part of the target language forms, norms or principles. In this respect, some responses have shown that some students have used the form 'excuse me' in the sense of 'I am sorry'. 


\section{Conclusions}

In the light of the analysis of learners' responses in section 4. and 5. above, some conclusions have been drawn as follows:

1- The misinterpretation or difficulty Iraqi EFL students have faced while trying to recognize and produce the speech act of apology is mainly attributed to their lack of socio-pragmatic knowledge. Accordingly, this has verified the first hypothesis of the study.

2- The socio-pragmatic failure has been attributed to the interference of the learners' first language culture. This kind of failure has resulted into non-native productions of speech act of apology. Most of these non-native apologies have been considered as direct translations of students' first language culture into the target language. Therefore, this has validated the second hypothesis.

3- Some responses have shown nonsensical interpretation owing to students' pragmatic inability to interpret the situations that call for apology and the result is non-apologetic responses. Other responses have shown that they lack the meanings of some of the lexical items found in the given situations. Consequently, they have produced responses with reference to other meanings not related to the given situations.

4- As far as the speech act of apology is concerned, semantic competence of Iraqi EFL university students does not assist them in recognizing and producing the speech act of apology appropriately in the given situations. However, their lack of pragmatic competence forces them to face difficulties in communicating apologies effectively and then lead them to fail. Consequently, what is mentioned in this point and point (3) have proved the third hypothesis.

5- Some responses have revealed that some students have faced difficulties in interpreting the given situations pragmatically in both recognition part and production part of the test. The reason behind these difficulties seems to lie behind their dependence on their mother-tongue in analyzing situations that call for apologies. Consequently, they have produced statements of apologies that are mainly influenced by their mother-tongue.

6- Scoring 170 out of the total score 700 , i.e. $22.8 \%$, in the production part of the test has revealed that Iraqi EFL university students not only face difficulties in producing the speech act of apology in natural communications but they are also unable to communicate apologies effectively.

\section{References}

Bach, X., \& Harnish, X. (1979). Linguistic communication and speech acts. Cambridge: MIT Press.

Crystal, D. (2008). A dictionary of linguistics and phonetics.( $6^{\text {th }}$ edition). Oxford: Blackwell Publishing.

Davies, B. L., Merrison, A. J \& Goddard, A. (2007). Institutional Apologies in UK Higher Education: Getting Back into the Black before Going into the Red. Journal of Politeness Research. 3, 39-63.

Deutschmann, M. (2003). Apologizing in British English. Umeå: Umeå Universitet.

Fraser, B. (1981). On Apologizing. In Florian Coulmas (ed.) Conversational routine: Explorations in standardized communication situations and pre-patterned speech. The Hague: Mouton.

Gill, K. (2000). The Moral Functions of an Apology. The Philosophical Forum. 31, 11-27.

Goffman, E. (1971). Relations in public: micro-studies of the public order. London: Penguin.

Holmes, J. (1990). Apologies in New Zealand English. Language in Society. 19, 155-199.

Lakoff, R. (2003). Nine Ways of looking at Apologies. In Schiffrin, D., Tannen D., \& Hamilton, E. Heidi (eds.) The handbook of discourse analysis. Oxford: Blackwell Publishing. 199-214.

Lazare, A. (2004). On apologizing. Oxford: Oxford University Press.

Leech, G. (1983). Principles of pragmatics, London: Longman.

Norrick, Neal R. (1978). Expressive Illocutionary Acts. Journal of Pragmatics. 2, 277-291.

Olshtain, E., \& Cohen, A. D. (1983). Apology: A speech Act Set. In Nessa Wolfson \& Elliot Judd (eds.) Sociolinguistics and language acquisition. Rowley, MA: Newbury House Publishers.

Slugoski, B. R. \& Turnbull, W. (1988). Cruel to Be Kind and Kind to Be Cruel: Sarcasm, Banter and Social Relation. Journal of Language and Social Psychology.7, 101-121. 